\title{
Design and Implementation of Student Leaders' Information System based on Web
}

\author{
Zhenyu $\mathrm{Xu}^{1, a}$, Zhaogang $\mathrm{Xie}^{2, \mathrm{~b}}$ \\ ${ }^{1}$ Tibet Vocational Technical College, Lhasa 850000, Tibet, China; \\ ${ }^{2}$ Shenzhen Polytechnic, Shenzhen 518055, Guangdong, China. \\ aft2027@163.com, bgeorgbush@szpt.edu.cn
}

Keywords: Higher vocational colleges, cultural quality education, training mode

\begin{abstract}
The paper takes a questionnaire survey to study the design and implementation of the student leaders' information system in Tibet. Tibet is located in the southwest border country, it's environment, history and culture as well as the national policy and so on all has certain particularity, it is the particularity to derive the regional higher education in Tibet, the student of Tibet university cadre training also is different from the mainland. In this paper, from the Tibetan college students, Tibet university group work and Tibetan cultural history of three aspects in this paper, the situation of Tibet university student cadre training in the optimization plan is proposed on the basis of investigating and analyzing the full and reasonable path.
\end{abstract}

\section{Introduction}

The Tibet is located in the southwest border, was magnificent, sparsely populated, and the average elevation of it is 4000 meters. Economically, in recent years, with the deepening of the development of the western region, Tibet's economy is gradually improving, but still far behind the eastern coastal areas; Politically, Tibet in the forefront of China's anti-secession struggle, for national unity, national unity and social stability is of great significance, but also it is an important barrier to China's national security, social employment, countries created a looser employment environment in Tibet, the competitive level is low.

The reality of Tibet special larger demand for talent, in order to achieve the leap development goals of Tibet will have to adapt to Tibet's economic and social development of all kinds of talents, this is all of the functions of institutions of higher learning, Tibet is the top priority. Current Tibet has only six colleges and universities, including three undergraduate colleges, vocational college three, low degree of standardization of higher education, the overall level is bad, need to be improved. And student leaders as a group of students in colleges and universities, is the backbone of the future construction of Tibet, to the community culture should be promoted to the strategic height of university construction, the development of Tibet.

\section{Analysis of the Status Quo}

Now Tibet has only one "211" college and the other universities is so weak. From the perspective of recruit students, most of the students with higher levels of knowledge go to the mainland, and the college students of mainland come to Tibet have low exam score. This situation is not conducive to the cultivation of the learning organization and learning backbone. At the same time, the Tibetan local college students, quite a number of written communication skills in mandarin Chinese is bad, the theoretical level of student cadres, ideological and political consciousness of ascension caused difficulties. Now, the western anti-china forces and the 14th Dalai Lama is still trying to split Tibet, the level of political consciousness of the young students and distinguish ability put forward higher requirements.

As is shown in Tab.1, colleges in Tibet, the administrative personnel let the student to work more. Exercise the student cadre's ability to execute, but suppresses the student cadre's subjective initiative and innovative thinking; To do a good job today, but ignored the long-term development 
of students' in future. At the same time for the linkage of the student cadre training mechanism is not sound, lack of standardization of the supervision and inspection mechanism, evaluation and institutionalized, systematic training mechanism, incentive mechanism for the cultivation of the student cadre level as a whole is low.

Table 1 The higher education development in Tibet between year 2005 and 2010

\begin{tabular}{ccccccc}
\hline & Year & Year & Year & Year & Year & Year \\
& 2005 & 2006 & 2007 & 2008 & 2009 & 2010 \\
\hline Gross enrollment rate & 13.2 & 16.3 & 17.4 & 19.7 & 22.4 & 23.4 \\
New college enrollment & 7589 & 8359 & 8046 & 8526 & 9020 & 9213 \\
College student enrollment & 18979 & 23327 & 26767 & 29409 & 30264 & 31109 \\
\hline
\end{tabular}

As influenced by objective factors like imbalanced distribution of education resources, the culture quality education is carried out on various levels in higher vocational colleges. There are significant differences in curriculum system, teachers and hardware facilities. China Higher Education Research takes a statistical analysis about the thesis published in the 14 core Chinese journals in the higher education field. It shows that though the number of the thesis published by the vocational colleges is rising at a large scale, the thesis are mostly written by the teachers in the top few higher vocational colleges, which suggests the national and local government equalize the distribution of resources that helps the balanced development of culture quality education.

Special geographical location and natural environment in Tibet, through long-term accumulation formed in the history of culture different from that of the mainland. Is an important part of Tibetan culture, Tibetan Buddhism in Tibet with a long history and far-reaching, many young students have been affected by the elders, made the resistance for the further popularization of Marxism-Leninism. Faith for college student cadres Marxism-Leninism and deep understanding of "the road of socialism with Chinese characteristics", "scientific development", "Chinese dream" and other mainstream trend is advantageous to the firm political direction of the young students in Tibet, far-reaching significance. Now the Tibet university students' mainstream trend of "national identity degree is higher.

Ideological and political education work for a college student's personality formation and career prospects are of great significance. Each college ideological work should be throughout the whole school departments, form a perfect education work system, selecting high consciousness and strong business, the teacher for ideological work. For now, Tibet university student cadre of the main way of civil service jobs after graduation, so the correct political orientation and the correct view of not just a matter of personal development, and even national stability and national unity. In view of the Tibet autonomous region special political environment and the need of local great-leap-forward development, Tibet universities ideological and political education should be placed in a strategic height, make full use of classroom communication "the road of socialism with Chinese characteristics", "Chinese dream" and other mainstream trend; Strengthen the construction of the "second classroom" with the help of the platform to preach the mainstream trend, proclaiming the guidelines and policies of the party and the country; To strengthen the construction of campus culture, by comparison with "new and old Tibet" and a series of activities to strengthen patriotism education, with cultural activities as the carrier, exercise people in practice, in practice achievements are excellent student cadre.

Now Tibet university student party member number is lower, quality remains to be improved, especially in vocational college, when a party member or a student cadre truly familiar with and adapt to group learning work often have faced after employment, graduate, this to a certain extent, reduce the colleges and universities to cultivate backbone of the party members and students enthusiasm. Amateur party school in the Tibet colleges and universities to cultivate the party activists as the main function, the cultivation of the student leaders can take this platform; 
encourage student cadres for non-party people participate in together. Strengthening students cadres for the history of the party, the party constitution, to help and guide the student cadres concerned about current events, encourage and assist students cadres to participate in the party's mass line education practice, make the non-party people of student cadre in the two aspects of the theoretical level and practical ability get promoted, which has general the advanced nature of party members.

Table 2 Comparison between different types of vocational schools

\begin{tabular}{cccccccccccccc}
\hline Year & \multicolumn{3}{c}{ Vocational schools } & \multicolumn{3}{c}{ Enrollment } & \multicolumn{4}{c}{ Students at school } \\
\hline & Numbers & High & Middle & Low & Numbers & High & Middle & Low & Numbers & High & Middle & Low \\
\hline 2000 & 20316 & 1.88 & 92.24 & 5.88 & 517.65 & 3.76 & 90.01 & 6.23 & 1658.52 & 2.18 & 92.47 & 5.35 \\
2001 & 18178 & 2.12 & 92.02 & 5.86 & 530.97 & 6.68 & 87.67 & 5.65 & 1588.78 & 4.51 & 90.24 & 5.25 \\
2002 & 16931 & 3.24 & 90.95 & 5.81 & 660.36 & 9.02 & 86.51 & 4.47 & 1696.90 & 7.05 & 88.03 & 4.92 \\
2003 & 16412 & 4.33 & 89.46 & 6.21 & 628.95 & 14.05 & 82.00 & 3.95 & 1518.93 & 12.49 & 82.74 & 4.77 \\
2004 & 16023 & 5.44 & 90.16 & 4.40 & 701.05 & 16.89 & 80.77 & 2.34 & 1730.94 & 15.50 & 81.42 & 3.08 \\
\hline
\end{tabular}

College counselor is the pioneer of Tibet university group learning work, is also an important force in student cadre training. Tibet is common universities head teachers too young, lack of work experience, low salary, full-time political instructor low proportion of many problems, strengthen the construction of college counselors from the following several aspects:

(1) Age structure optimization of counselor team. On the one hand must pay attention to training of young instructors, but also to make a more experienced group learning workers to remain in the group learning post, also, constantly absorbing the new strength, make the counselors team gradually formed "in the old, middle-aged and young age structure, the formation of" pass, help, take "the good atmosphere.

(2) Strengthen counselor re-education. Now Tibet region are widespread counselor problems such as irrational knowledge structure, lack of work experience, the best way to solve is continuously through lectures, seminars, study methods such as strengthening the counselor work out ability. Tibetan areas, in particular, should make more counselors can "go out", mutual exchange of learning to improve, in order to better interact study work in the future, the service student cadre training.

(3) Attaches great importance to the working method and working process. Instructor and student cadres training work is a long-term and arduous task, its results not visible overnight, so more should abandon the "get rich quick" way of thinking and working methods. Fully respect the Tibetan history and culture in the work, with respect to win respect. Emphasis should be paid on innovation, flexible use of job skills, work experience in reference to mainland universities, but not "copying", according to the present condition of Tibet.

\section{Measures}

In terms of student cadre selection, promotion, make a standard shall establish corresponding rules and regulations, with the help of a group learn the fixed pattern, such as generation will be in the form of fair, fair and open recruitment and selection. Especially the monitor, competitive person, minister of the student union, members of the presidium of student union selection shall be by secret ballot student representative, avoid by all means is the teacher specified in private. Thus not only strengthened the student cadre's credibility and more can fully exercise the student cadre ability of the business.

In terms of student cadre assessment, incentive, traditional recognition activities should be combined with a festival node, make quantitative evaluation standard, constantly stimulate the student cadre work enthusiasm. Strengthen the student cadre "humanistic care", "material rewards" 
and "inspired" organic combination. In addition, the work is not positive student cadre should take criticism education or general election, maintain the vitality of student cadres.

In terms of student cadre training, have since ancient times the thought of "according to their aptitude". But from the school level, training from the training of student cadres must have extensive sex, in comprehensive content; the student cadre has the certain choice. Of student cadre training should be long-term system, make its work in group to learn from sex. In addition, the concept of cultivating student cadre should be through daily group learning work, can't just rely on general forms such as lectures, find the disadvantage of student cadres, to rectify the problem.

Improve the cultural quality education curriculum system. Though it is difficult to clearly divide the curriculum system, in order to better illustrate the construction of culture quality education curriculum system, the paper tries to divide the curriculum system into three aspects, the courses arrangement, and practice activities and the soft environment. The courses arrangement refers to the construction of culture quality education system composed of compulsory and elective courses. The practice activities cover a lot of areas, such as the activities performed by the CYL committee or Students' Union at campus, the internships and different social practices. The soft environment mainly refers to the construction of campus culture and network environment. To promote the construction of the culture quality education system, there are a few points that need to be paid attention to. First, change the traditional ways of classifying the liberal arts courses as selective courses to compulsory courses which helps increase the importance of culture quality education. Second, carry out social practice course and psychological health course on a whole school scale. This will help to lay a good psychological and practical knowledge foundation for the students to enhance the culture quality education.

In colleges and universities student cadre in the basic "after 90" as the main force, this generation is often as an only child, and relatively superior growth environment, lead to the setback ability is relatively poor. Student cadre psychological fluctuations are often encountered in the work life vulnerable to learn workers neglect, not conducive to the growth of student cadres. Colleges and universities should make full use of resources, face-to-face to carry out various forms of team activities and rich content of counseling lectures; To set up the "mental QQ room," get psychological counseling teachers to solve psychological dilemma; To set up the "mental health", and guide students' extracurricular activities, the rich campus culture at the same time help more students to set up the sunshine, healthy state of mind.

\section{Summary}

As the Tibetan areas of the development and utilization of natural resources and regional economic development, local society's need for talents more and more urgent, pay more attention to the cultivation of college student cadres' work should be upgraded to the height of strategy. The basis of Tibetan education as well as the institutions of higher learning education levels will under the joint efforts of all the education workers. At the same time, Tibet university learn workers continue to learn on the way to cultivate students cadres, and to explore, were walking on the right path, while facing the particularity of Tibetan areas, and many difficulties, but as long as we hold the basic rule of group learning work, seek truth from facts, dare to innovation, will be for countries, for the country to cultivate a batch for Tibet "is life, the use, reliable" qualified builders and reliable successors.

\section{References}

[1] D. S. Chen: Journal of Tibet University for Nationalities, vol.3 (2006), p.89 - 92. (In Chinese)

[2] M. Chen: Business Review, vol.1 (2011), p. 88 - 90. (In Chinese)

[3] L.X. Kong: Journal of University of Tibet, vol.12 (2011), p. 29 - 31. (In Chinese)

[4] F. Yang: Tibet Education, vol.7 (2012), p.51 - 53. (In Chinese) 
[5] H. He: Education Teaching Forum, vol.3 (2011), p.179 - 180. (In Chinese) 